\title{
Optimasi Konsentrasi Span 80 dan Lama Pengadukan dalam Preparasi Microspheres Metformin Hidroklorida-kitosan (Optimization of Span 80 Concentration and Stiring Time on The Preparation of Metformin Hydrochloride-Chitosan Microspheres )
}

\author{
Christyn Novyta S, Lusia Oktora Ruma Kumala Sari, Eka Deddy Irawan \\ Fakultas Farmasi, Universitas Jember \\ Jln. Kalimantan 37, Jember 68121 \\ e-mail korespondensi: oktora@unej.ac.id
}

\begin{abstract}
Metformin hydrochloride (MH) has been used as first line for type 2 diabetes mellitus treatment. However, it has relatively low bioavailability, short half-life and could cause gastrointestinal side effects, therefore it is appropriately prepared as microspheres. Microspheres is micro particle which is between 1-1,000 $\mu \mathrm{m}$ in size. Many factors affected the result of microspheres preparation, such as surfactant concentration and stirring time. This research was aimed to find the best composition of span 80 concentration and stirring time to produce $\mathrm{MH}$-chitosan $(\mathrm{CH})$ microspheres with the highest entrapment efficiency (EE) using factorial design optimization. MH was used as active substance, $\mathrm{CH}$ as polymer, span 80 as surfactant and non-aqueous solvent evaporation method was chosen for microspheres preparation technique. The optimized formula $2 \%$ span 80 and 2 hours stirring time gained $86.803 \pm 0.544 \%$ EE, $24.571 \pm$ $0.157 \%$ drug loading, and $88.220 \pm 0.137 \%$ yield. The microspheres had a relatively smooth, bright surface, and spherical structure. The average particle's size was $161.2 \pm$ $1.743 \mu \mathrm{m}$. FTIR analysis indicated that there were no changes in the spesific functional clusters of $\mathrm{MH}$ as an active substance.
\end{abstract}

Keywords: metfomin-hydrocloride-chitosan microspheres, non-aquoeous solvent evaporation, factorial design, span 80 concentration, stirring time.

\begin{abstract}
Abstrak
Metformin hidroklorida (MH) merupakan lini pertama untuk terapi diabetes melitus tipe 2, namun memiliki bioavailabilitas yang relatif rendah, waktu paruh yang singkat dan dapat menimbulkan efek samping pada saluran pencernaan sehingga $\mathrm{MH}$ tepat dipreparasi menjadi sediaan microspheres. Microspheres merupakan mikropartikel memiliki rentang ukuran 1-1.000 $\mu \mathrm{m}$. Banyak faktor yang mempengaruhi hasil preparasi microspheres di antaranya adalah konsentrasi Surfaktan (span 80) dan lama pengadukan yang digunakan. Penelitian ini bertujuan untuk mengetahui komposisi terbaik konsentrasi span 80 dan lama pengadukan yang dapat menghasilkan microspheres $\mathrm{MH}-\mathrm{CH}$ dengan entrapment efficiency (EE) tertinggi menggunakan optimasi desain faktorial. $\mathrm{MH}$ digunakan sebagai bahan aktif, kitosan digunakan sebagai polimer, dan span 80 sebagai surfaktan serta non-aqueous solvent evaporation method sebagai teknik yang dipilih dalam preparasi microspheres. Hasilnya microspheres yang menggunakan konsentrasi span $802 \%$ dan lama pengadukan selama 2 jam menghasilkan EE sebesar $86,803 \pm 0,544 \%$, drug loading sebesar $24,571 \pm 0,157 \%$ dan yield sebesar $88,220 \pm 0,137 \%$. Microspheres memiliki permukaan yang relatif halus,cerah, dan berbentuk sferis serta rata-rata ukuran partikel sebesar 161,2 $\pm 1,743 \mu \mathrm{m}$. Hasil analisis FTIR menunjukkan bahwa tidak ada perubahan gugus fungsi spesifik pada $\mathrm{MH}$ sebagai bahan aktif.
\end{abstract}

Kata kunci: microspheres metformin hidroklorida-kitosan, non-aquoeous solvent evaporation, desain faktorial, konsentrasi span 80 , lama pengadukan 


\section{Pendahuluan}

Metformin hidroklorida $\quad(\mathrm{MH})$ merupakanadalah lini pertama terapi diabetes mellitus tipe 2 [1]. Rumus molekul $\mathrm{MH}$ adalah $\mathrm{C}_{4} \mathrm{H}_{11} \mathrm{~N}_{5} \cdot \mathrm{HCl}$ [2]. Dosis $\mathrm{MH}$ pada sediaan konvensional yang digunakan umumnya sebesar $500 \mathrm{mg}$ untuk pemakaian 2-3 kali sehari atau $850 \mathrm{mg}$ untuk pemakaian sekali atau dua kali sehari dengan bioavailabilitas sebesar $50-60 \%$ dan waktu paruh yang pendek yaitu $1,5-4,5$ jam [3].

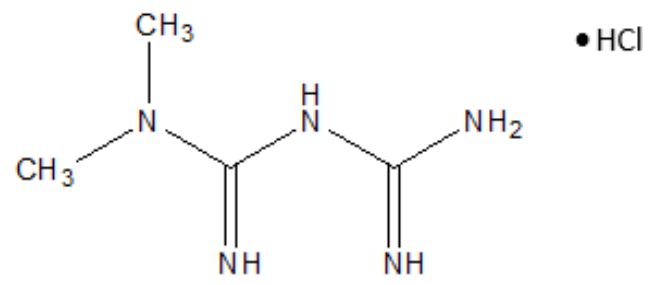

Gambar 1. Struktur MH mengandung gugus biguanida yang tersubstitusi dua gugus metil.

Penggunaan $\mathrm{MH}$ dengan dosis yang besar dan secara berulang memungkinkan terjadinya gangguan gastrointestinal yang menimbulkan efek samping seperti perut terasa tidak nyaman, mual dan diare [4]. Pengembangan sistem pelepasan obat terkendali obat memliki potensi besar untuk mengatasi permasalahan tersebut dengan melepaskan obat secara perlahan pada saluran gastrointestinal dan mempertahankan konsentrasi obat di sirkulasi sistemik dalam waktu yang lama [5].

Microspheres merupakan salah satu teknologi farmasi dalam sistem penghantaran obat terkendali yang menggunakan bahan polimer sebagai pembawa [6]. Microspheres merupakan mikropartikel yang bersifat homogen dan molinitik dengan ukuran 1-1.000 $\mu \mathrm{m}$ [7].

Metode solvent evaporation banyak digunakan dan lebih disukai dalam pembuatan microspheres untuk sistem penghantaran obat terkendali karena kemudahan aplikasinya dengan menggunakan alat-alat laboratorium umum dan tanpa menurunkan aktivitas dari bahan aktif [8]. Salah satu tipe dari metode solvent evaporation adalah non-aqueous solvent evaporation. Metode ini tidak menggunakan air sebagai pelarut sehingga cocok digunakan sebagai metode pembuatan microspheres dengan bahan obat yang bersifat larut air. Preparasi microspheres dengan teknik non aqueous solvent evaporation menggunakan $\mathrm{MH}$ sebagai bahan aktif, $\mathrm{CH}$ sebagai bahan polimer [9] dan span 80 sebagai surfaktan [10].

Span 80 digunakan sebagai em/sifying agent yang akan menghasilkan emulsi air dalam minyak yang stabil dan mikroemulsi [11]. Span 80 dapat mempertahankan droplet-droplet yang telah terbentuk agar tidak menyatu lagi menjadi polimer [12].

Entrapment efficiency (EE) merupakan salah satu faktor keberhasilan suatu preparasi microspheres. Nilai EE digunakan untuk menunjukkan seberapa besar jumlah obat yang terperangkap di dalam partikel microspheres. Banyak faktor yang mempengaruhi nilai EE. Menurut penelitian yang dilakukan oleh Maji et al. [10] dan Garud \& Garud [9] terdapat hubungan antara konsentrasi span 80 dan lama pengadukan yang digunakan terhadap nilai EE pada microspheres yang dihasilkan. Berdasarkan hal tersebut maka perlu dilakukan optimasi konsentrasi span 80 dan lama pengadukan untuk memperoleh respon EE tertinggi.

\section{Metode Penelitian}

Jenis penelitian ini adalah penelitian eksperimental laboratorik yang dilaksanakan di Laboratorium Teknologi Sediaan Solida Bagian Farmasetika dan Laboratorium Kimia Analisis Bagian Kimia Farmasi Fakultas Farmasi Universitas Jember. Bahan yang digunakan dalam penelitian ini adalah $\mathrm{MH}$ sebagai bahan aktif (Zenith Pharmaceutical), $\mathrm{CH}$ sebagai polimer (Lawsim Zecha), span 80 sebagi surfaktan (Brataco Chemika), metanol sebagai fase internal (Brataco Chemika), aseton sebagai fase internal (Smart Lab. Indonesia), parafin cair sebagai fase eksternal (Brataco Chemika), dan petroleum eter sebagai agen pencuci (Brataco Chemika).

Penentuan jumlah formula yang akan dipreparasi dalam penelitian dilakukan menggunakan desain faktorial dua faktor dua level. Tiap formula memiliki jumlah bahan aktif yang sama, yang membedakan konsentrasi span 80 yang digunakan dan lama pengadukan four blades propeller dalam preparasi microspheres $\mathrm{MH}$. Pemilihan level rendah dan level tinggi pada masing-masing faktor ditentukan berdasarkan hasil penelitian sebelumnya. Preparasi microspheres $\mathrm{MH}-\mathrm{CH}$ untuk masing-masing formula dapat dilihat pada Tabel 1. 
Tabel 1. Preparasi microspheres metformin- $\mathrm{CH}$

\begin{tabular}{ccccc}
\hline $\mathrm{F}$ & $\begin{array}{c}\mathrm{MH} \\
(\mathrm{mg})\end{array}$ & $\begin{array}{c}\mathrm{CH} \\
(\mathrm{mg})\end{array}$ & $\begin{array}{c}\text { Span } \\
80 \\
(\%)\end{array}$ & $\begin{array}{c}\text { Lama } \\
\text { pengadukan } \\
\text { (jam) }\end{array}$ \\
\hline 1 & 750 & 2250 & 2 & 2 \\
$\mathrm{~A}$ & 750 & 2250 & 6 & 2 \\
$\mathrm{~B}$ & 750 & 2250 & 2 & 4 \\
$\mathrm{AB}$ & 750 & 2250 & 6 & 4 \\
\hline
\end{tabular}

Preparasi microspheres dengan metode non-aqueous solvent evaporation dilakukan dengan mencampurkan dispersi $\mathrm{MH}$ dalam 5 $\mathrm{ml}$ metanol dengan larutan $\mathrm{CH}$ dalam $24 \mathrm{ml}$ aseton. Campuran tersebut dimasukkan ke dalam $50 \mathrm{ml}$ parafin cair yang mengandung span $802 \% \mathrm{v} / \mathrm{v}$ dan $6 \% \mathrm{v} / \mathrm{v}$, kemudian dilakukan pengadukan menggunakan four blades propeller kecepatan $400 \mathrm{rpm}$ pada suhu ruang. Microspheres yang terbentuk disaring dengan menggunakan penyaring vakum dilengkapi kertas Whatman no 1. Serbuk microspheres yang terbentuk dicuci menggunakan petroleum eter suhu $30^{\circ} \mathrm{C}$ kemudian dikeringkan dalam oven suhu $60^{\circ} \mathrm{C}$ sampai didapatkan berat microspheres yang konstan.

Sejumlah microspheres yang ekuivalen dengan $5 \mathrm{mg} \mathrm{MH}$ dibilas menggunakan akuades untuk menghilangkan $\mathrm{MH}$ bebas. Microspheres kemudian dihancurkan dalam mortir, dilarutkan dengan akuades sampai dengan $100 \mathrm{ml}$ dan disaring. Filtrat selanjutnya diencerkan 10 kali dan dianalisis menggunakan spektrofotometer UV pada panjang gelombang $233 \mathrm{~nm}$ untuk menentukan konsentrasi obat. Cara penentuan EE yaitu dengan membandingkan konsentrasi obat sebenarnya dengan konsentrasi obat teoritis lalu dikali $100 \%$.

Nilai EE yang diperoleh dari masingmasing formula dinyatakan sebagai respon yang diamati pada penelitian ini. Respon kemudian dimasukkan dalam software design expert 10.0.2 versi trial untuk mendapatkan formula optimum. Berdasarkan hasil pengolahan data dapat diketahui efek faktor serta interaksinya terhadap respon, kemudian untuk mengetahui komposisi optimum kombinasi konsentrasi span 80 dan lama pengadukan yang menghasilkan nilai EE tertinggi dapat diketahui melalui contour plot dan overlay plot.

Formula optimum microspheres $\mathrm{MH}$ yang dihasilkan berdasarkan software design expert 10.0.2 versi trial selanjutnya dibuat. Verifikasi
EE kemudian dilakukan untuk mengetahui seberapa besar kemiripan EE hasil prediksi dengan hasil percobaan. Formula optimum selanjutnya dilakukan karakterisasi meliputi drug loading (DL), yield, analisis fourier transform infrared (FTIR), dan scanning electron microscopy (SEM). Perhitungan DL yaitu dengan cara EE dikali berat $\mathrm{MH}$ sebenarnya dibagi dengan berat microspheres yang didapat lalu dikali $100 \%$. Nilai yield didapat dengan cara membagi berat microspheres yang didapat dari hasil preparasi dengan berat microspheres teoritis lalu dikali $100 \%$.

Analisis FTIR dilakukan dengan membandingkan pola spektum microspheres dengan standar metformin hidroklorida dan kitosan. Spekrum FTIR dari microspheres, metformin hidroklorida dan kitosan diukur pada bilangan gelombang antara $4000-500 \mathrm{~cm}^{-1}$.

SEM dilakukan dengan meletakkan sejumlah microspheres disebarkan dan ditempelkan menggunakan selotip karbon pada bagian stub lalu ditempatkan di scanning electron chamber. Pemindaian dilakukan pada pembesaran yang berbeda-beda.

\section{Hasil Penelitian}

Hasil pembuatan empat formula microspheres $\mathrm{MH}-\mathrm{CH}$ dapat dilihat pada Gambar 2. Keempat formula tersebut memiliki penampakan yang hampir sama yaitu serbuk putih agak kekuningan. Hasil uji EE masingmasing formula ditunjukkan oleh Tabel 2.
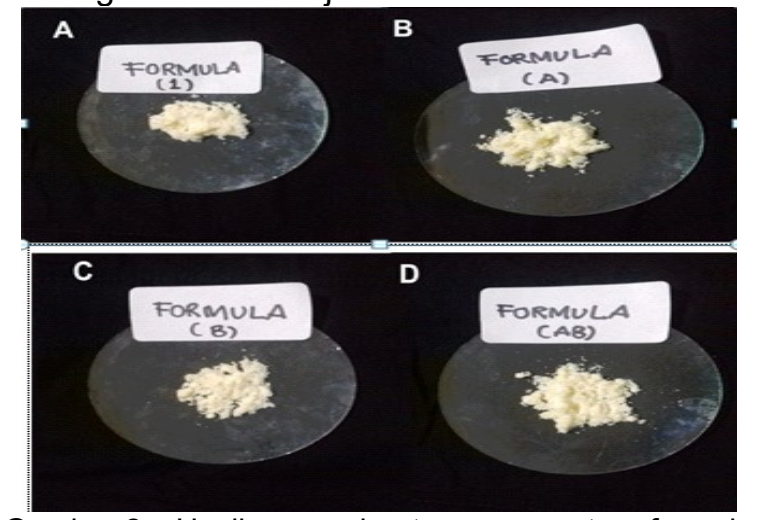

Gambar 2. Hasil pembuatan empat formula microspheres $\mathrm{MH}-\mathrm{CH}$ : (A) konsentrasi span $802 \%$ dan pengadukan 2 jam; (B) konsentrasi span $80 \quad 6 \quad \% \quad$ dan pengadukan 2 jam; (C) konsentrasi span $806 \%$ dan pengadukan 4 jam; (D) konsentrasi span $80 \quad 6 \quad \% \quad$ dan pengadukan 4 jam.

Nilai EE dari masing-masing formula selanjutnya dimasukkan dalam software design 
expert 10.0.2 versi trial sehingga didapatkan Persamaan 1. Software design expert 10.0 .2 versi trial juga dapat memberikan contour plot dan overlay plot. Gambar contour plot dapat dilihat pada Gambar 3. Contour plot menggambarkan efek konsentrasi span 80 dan lama pengadukan terhadap EE. Daerah yang berwarna biru memiliki EE prediksi yang paling rendah sedangkan daerah berwarna merah memiliki EE prediksi yang paling tinggi. Semakin rendah konsentrasi span 80 dan semakin rendah lama pengadukan yang digunakan maka akan meningkatkan nilai EE.

Tabel 2. Hasil pengujian EE tiap formula

\begin{tabular}{cccc}
\hline $\mathrm{F}$ & $\begin{array}{c}\mathrm{MH} \\
(\mathrm{mg})\end{array}$ & $\begin{array}{c}\mathrm{CH} \\
(\mathrm{mg})\end{array}$ & $\begin{array}{c}\text { Span } 80 \\
(\%)\end{array}$ \\
\hline 1 & 2 & 2 & $87,143 \pm 0,085$ \\
$\mathrm{~A}$ & 6 & 2 & $58,898 \pm 1,172$ \\
$\mathrm{~B}$ & 2 & 4 & $70,229 \pm 1,408$ \\
$\mathrm{AB}$ & 6 & 4 & $53,388 \pm 1,203$
\end{tabular}

${ }^{*}$ data disajikan dalam rerata \pm SD $(n=3)$

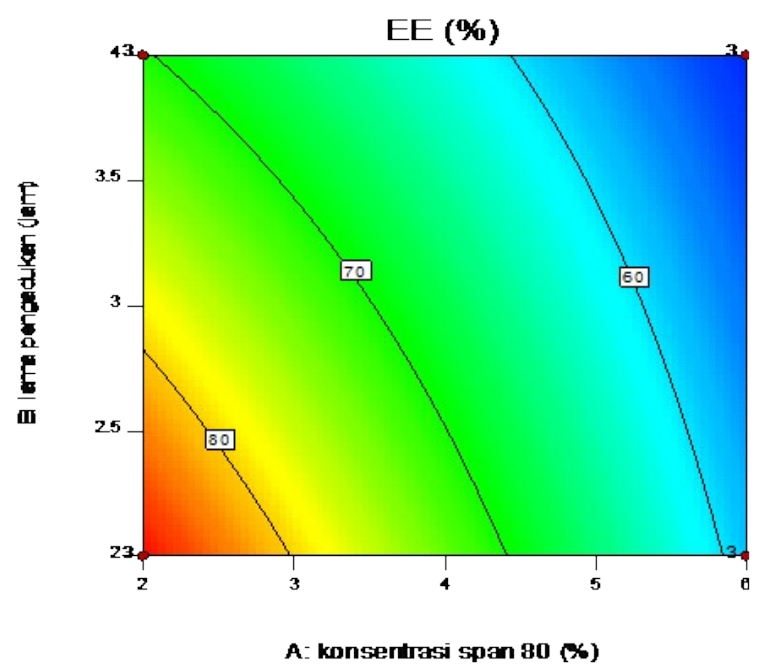

Gambar 3. Contour plot konsnetrasi span 80 dan lama pengadukan terhadap EE

Grafik overlay plot digunakan untuk menentukan daerah optimum respon EE yang ditunjukkan oleh daerah berwarna abu-abu dan kuning. Respon EE di atas $60 \%$ didapatkan pada daerah berwarna kuning, sedangkan pada daerah berwarna abu-abu didapatkan respon EE di bawah 60 \%. Pada daerah warna kuning dapat dibuat flag di sembarang titik yang akan menampilkan konsentrasi span 80 dan lama pengadukan beserta respon yang dihasilkan pada titik tersebut. Gambar overlay plot dapat dilihat pada Gambar 4.

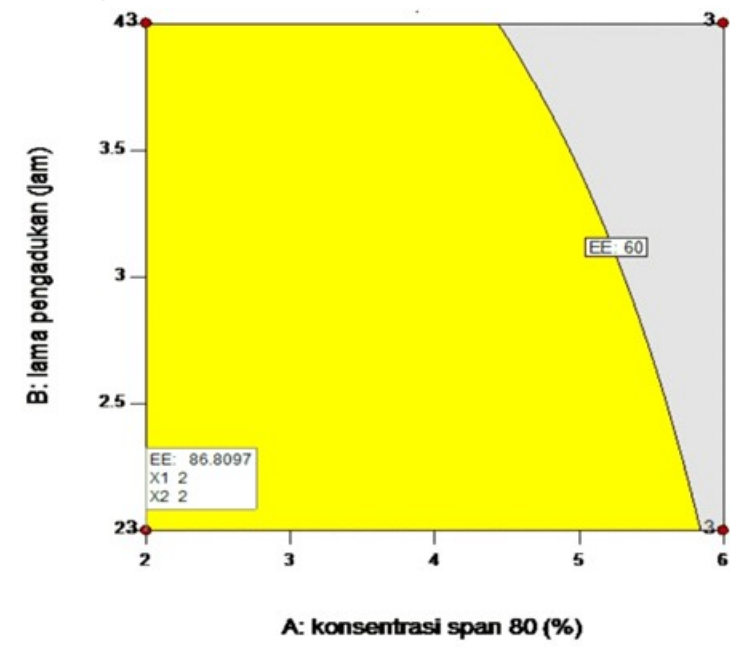

Gambar 4. Overlay plot respon EE.

Hasil pengujian EE formula optimum terpilih yaitu menggunakan span 80 konsentrasi $2 \%$ dan lama pengadukan 2 jam yaitu sebesar $87,143 \pm 0,085 \%$, sedangkan EE hasil prediksi software design expert 10.0.2 versi trial adalah sebesar 86,803 \%. Hasil verifikasi EE memberikan kemiripan sebesar 99,609 \%. Hasil karakterisasi formula optimum menunjukkan bahwa microspheres $\mathrm{MH}$ memiliki nilai DL dan yield masing-masing sebesar $24,571 \pm 0,157 \%$ dan $88,220 \pm 0,137 \%$.

Hasil analisis FTIR menunjukkan bahwa tidak ada perubahan gugus fungsi pada microspheres $\mathrm{MH}-\mathrm{CH}$ ditandai dengan adanya kesamaan puncak yang khas $\mathrm{MH}$ murni yaitu $\mathrm{N}$ $\mathrm{H}$ primer pada bilangan gelombang gelombang $3.154 \mathrm{~cm}^{-1}, \mathrm{~N}-\mathrm{H}$ tekuk dari amino primer pada bilangan gelombang $1.562 \mathrm{~cm}^{-1}$, dan C-N pada bilangan gelombang $1064 \mathrm{~cm}^{-1}$. Hasil analisis FTIR microspheres $\mathrm{MH}-\mathrm{CH}$ ditampilkan dalam Gambar 5.

Hasil karakterisasi ukuran partikel, bentuk dan morfologi microspheres $\mathrm{MH}-\mathrm{CH}$ menggunakan SEM didapat microspheres berbentuk serbuk halus, berwarna putih kekuningan dengan rerata ukuran partikel sebesar 161,2 $\pm 1,743 \mu \mathrm{m}$. Morfologi microspheres $\mathrm{MH}-\mathrm{CH}$ memilki bentuk sferis, permukaan yang relatif halus, dan berwarna cerah. Morfologi microspheres dapat dilihat pada Gambar 6 dengan pembesaran 600x. 


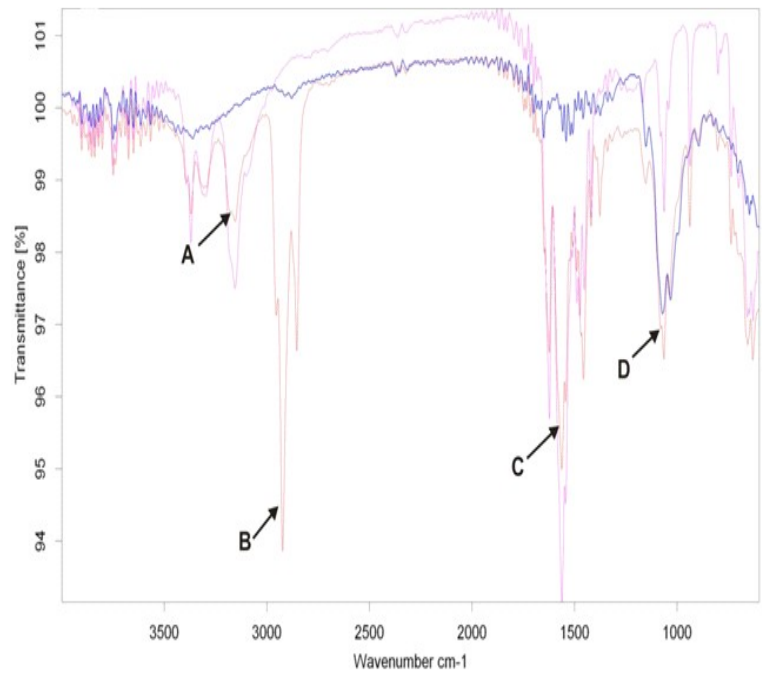

Gambar 5. Hasil spektra FTIR MH (ungu), $\mathrm{CH}$ (biru) dan microspheres $\mathrm{MH}-\mathrm{CH}$ (merah) menunjukkan adanya gugus fungsi yang khas pada $\mathrm{MH}$ yaitu: (A) N-H primer pada $3.154 \mathrm{~cm}-1$; (B) C-O asam karboksilat $2.992 \mathrm{~cm}-1$; (C) N-H tekuk primer pada $1.562 \mathrm{~cm}-1$; (D) C-N pada $1.064 \mathrm{~cm}-1$.

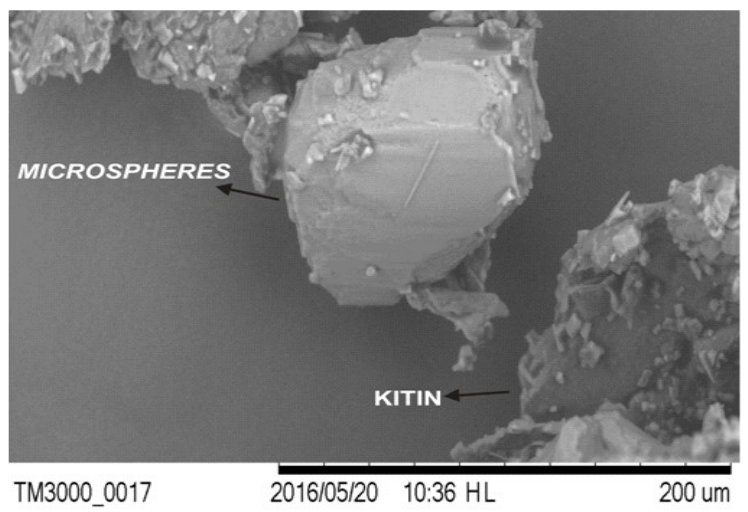

Gambar 6. Hasil analisis SEM dengan perbesaran $600 x$

\section{Pembahasan}

Hasil analisis software design expert 10.0.2 versi trial menunjukkan bahwa konsentrasi span 80 dan lama pengadukan serta interaksi keduanya memiliki pengaruh yang signifikan terhadap respon EE yang didapatkan. Hal ini ditunjukkan dari persamaan yang dihasilkan dan contour plot yang menggambarkan semakin tinggi konsentrasi span 80 dan semkain lama pengadukan yang dilakukan maka terjadi pergeseran ke arah berwarna biru, yang menunjukkan daerah dengan respon EE paling rendah.
Konsentrasi span 80 dapat mempengaruhi nilai EE yang dihasilkan. Semakin tinggi konsentrasi span 80 digunakan akan menyebabkan penurunan nilai EE. Hal ini dikarenakan semakin tinggi konsentrasi span 80 yang digunakan akan menyebabkan crowded yang akan meyebabkan droplet yang terbentuk tidak stabil dan pecah. Span 80 berfungsi sebagai penstabil droplet sehingga tidak menyatu lagi [12]. Hal ini sejalan dengan penelitian yang dilakukan oleh Maji et al [10] dan Mohanty \& Panigrahi [13] bahwa peningkatan konsentrasi span 80 dapat menyebabkan penurunan nilai EE.

Lama pengadukan juga mempengaruhi EE yang dihasilkan oleh suatu microspheres. Pengadukan yang terlalu singkat menyebabkan proses emulsi untuk pembentukan microspheres belum sepenuhnya terjadi dan bahan aktif belum sepenuhnya terjerap dalam partikel microspheres. Sebaliknya, proses pengadukan yang terlalu lama dapat menyebabkan penurunan EE karena adanya penurunan ukuran partikel microspheres yang diperoleh. Penurunan ukuran partikel menyebabkan penurunan kemampuan microspheres dalam menjerap bahan aktif sehingga akan menurunkan nilai EE. Hal ini sejalan dengan penelitian yang dilakukan oleh Rathod et al. bahwa peningkatan lama pengadukan yang dilakukan dapat menurunkan nilai EE [15].

Formula optimum terpilih yaitu formula dengan EE prediksi tertinggi. Berdasarkan Gambar 5. Dipilih formula optimum dengan faktor konsentrasi span $802 \%$ (level rendah) dan faktor lama pengadukan 2 jam (level rendah) yang diprediksi menghasilkan EE sebesar 87,143\%. Hasil verifikasi EE formula optimum didapatkan hasil bahwa EE hasil percobaan memiliki nilai yang berdekatan dengan EE hasil prediksi.

Karakterisasi DL digunakan untuk menunjukkan seberapa efisien formula yang digunakan. DL yang didapatkan dari formula optimum memiliki nilai yang berdekatan dengan penelitian yang dilakukan oleh Baddha et al [15].

Nilai yield membantu menentukan metode yang tepat karena dapat menunjukkan seberapa efisien metode yang digunakan untuk menghasilkan microspheres yang maksimum [7]. Yield yang mendekati $100 \%$ menunjukkan bahwa metode non-aqueous solvent evaporation yang digunakan dalam preparasi microspheres $\mathrm{MH}-\mathrm{CH}$ menghasilkan jumlah microspheres yang maksimal dengan efisien. 
Analisis FTIR pada Gambar 5 menunjukkan tidak adanya perubahan gugus fungsi yang khas pada $\mathrm{MH}$ sehingga preparasi microspheres tidak menganggu gugus spesifik dari $\mathrm{MH}$. Hal ini sejalan dengan penelitian yang dilakukan oleh Maji et al [10] bahwa preparasi microspheres $\mathrm{MH}-\mathrm{CH}$ menggunkan span 80 menunjukkan tidak adanya interaksi yang terbentuk antara obat, polimer dan bahan tambahan lainnya.

Hasil penentuan ukuran partikel didapatkan bahwa microspheres $\mathrm{MH}-\mathrm{CH}$ memiliki rata-rata ukuran partikel 161,2 \pm 1,73 $\mu \mathrm{m}$. Hal ini sesuai dengan persyaratan yang ditetapkan bahwa microspheres adalah partikel dengan rentang ukuran 1-1.000 $\mu \mathrm{m}$ [7].

Berdasarkan hasil karakterisasi tersebut maka preparasi microspheres $\mathrm{MH}-\mathrm{CH}$ dengan metode non-aqueous solvent evaporation dapat dikatakan berhasil. Namun keberhasilan suatu preparasi microspheres juga perlu diikuti dengan pengujian biovailabilitas in vivo dan in vitro untuk mengetahui keberhasilan microspheres sebagai sistem penghantaran obat terkendali. Selain itu juga perlu dilakukan pengujian mutu sediaan untuk mengetahui stabilitas sediaan microspheres.

\section{Simpulan dan Saran}

Hasil penelitian menunjukkan bahwa konsentrasi span 80 dan lama pengadukan terbukti memiliki pengaruh yang signifikan pada nilai EE microspheres $\mathrm{MH}-\mathrm{CH}$ yang dihasilkan. Kombinasi optimum antara konsentrasi span 80 dan lama pengadukan untuk memperoleh nilai EE maksimum adalah $2 \%$ selama 2 jam.

Penelitian yang perlu dikembangkan selanjutnya adalah pengujian disolusi, biovailabilitas dan stabilitas untuk mengetahui profil pelepasan, profil biovailabilitas serta mutu sediaan microspheres.

\section{Ucapan Terima Kasih}

Penulis mengucapkan terima kasih kepada PT. Zenith Pharmaceutical, Semarang, Indonesia yang telah memberikan bantuan bahan aktif metformin hidroklorida.

\section{Daftar Pustaka}

[1] Nathan DM, Buse JB, Davidson MB. Management of hyperglycemia in type 2 diabetes: a consensus statement from the american diabetes association and the european association for the study of diabetes. Diab Care. 2009; 32: 193.

[2] Sweetman SC. Martindale $36^{\text {th }}$ ed. USA: Pharm Press; 2009.

[3] Pandit V, Pai RS, Yadav V, Devi K, Surekha B B, Inamdar MN, Suresh S. Pharmacokinetic and pharmacodynamic evaluation of floating microspheres of metformin hydrochloride. Drug Dev Indian Pharm. 2013; 39(1): 117-27.

[4] Pilmore HL. Review: Metformin: Potential benefits and use in chronic kidney disease. Asian Sos Neph. 2010; 15: 412 418.

[5] Streubel A, Siepmann J, Bodmeier R. Drug delivey to the upper small intestine window using gastroretentive technologies. Sci Dir. 2006; 6(5): 501508.

[6] Hire, Derle. Microsphere as drug carrier: a review. Int. J. Adv.Res. 2014; 2(3), 901-913.

[7] Wise DL. Handbook of pharmaceutical controlled release technology. New York: Marcel Dekker Inc; 2000.

[8] Herrmann J, Bodmeier R. Biodegradable, somatostatin acetate containing microspheres prepared by various aqueous and non-aqueous solvent evaporation methods. Europ. J. Pharm. Biopharm. 1998;45(1), 75-82.

[9] Garud N, Garud A. Preparation and invitro evaluation of metformin microspheres using non-aqueous solvent. Topic J Pharm Res. 2012 August; 11(May): 577-583.

[10] Maji R, Ray S, Das B, Nayak. Ethyl cellulose microparticles containing metformin hydrochloride by emulsification-solvent evaporation technique: effect of formulation variables. Int Sci. 2012; 1-7.

[11] Rowe RC, Sheskey PJ, Quinn ME. Handbook of pharmaceutical excipient $6^{\text {th }}$ ed. London: Pharm Press And American Pharm; 2009.

[12] Pauchau L, Sarkar S, Mazumder, B. The study of the effect of surfactants on ethylcellulose microspheres containing salbutamol sulphate. Schol. Res. Lib.2009; 1 (1):65-74

[13] Mohanty S, Panigrahi AK. Preparation of 5-floroucil microspheres for colonic drug delivery. Int J Pharm .2014; 4(3): 283-296

[14] Rathod UC, Patel AK, Shah DA. Statistical evaluation and optimization of 
Sianipar, et al, Optimasi Konsentrasi Span 80 dan Lama Pengadukan dalam Preparasi Microspheres.....

influence of stirring speed and polymer concentration on hollow microspheres of diltiazem hydrochloride. Schol Res Lib. 2012; 4(3): 972-978.

[15] Badhana S, Garud N, Garud A. Colon specific drug delivery of mesalamine using eudragit S100-coated chitosan microspheres for the treatment of ulcerative colitis. Int. Curr. J. Pharm. 2013, 2(3): 42-48 